\title{
Early Detection of Ganoderma Basal Stem Rot of Oil Palms Using Artificial Neural Network Spectral Analysis
}

Parisa Ahmadi, Department of Agriculture Technology, Faculty of Agriculture, Universiti Putra Malaysia, 43400 Serdang, Selangor, Malaysia; Farrah Melissa Muharam, Department of Agriculture Technology, Faculty of Agriculture, Universiti Putra Malaysia, 43400 Serdang, Selangor, Malaysia; Geospatial Information Science Research Centre, Faculty of Engineering, Universiti Putra Malaysia, 43400 Serdang, Selangor, Malaysia; and Institute of Plantation Studies, Universiti Putra Malaysia, 43400 Serdang, Selangor, Malaysia; Khairulmazmi Ahmad, Department of Plant Pathology, Faculty of Agriculture, Universiti Putra Malaysia, 43400 Serdang, Selangor, Malaysia; Shattri Mansor, Department of Civil Engineering, Faculty of Engineering, Universiti Putra Malaysia, 43400 Serdang, Selangor, Malaysia; and Geospatial Information Science Research Centre, Faculty of Engineering, Universiti Putra Malaysia, 43400 Serdang, Selangor, Malaysia; and Idris Abu Seman, Malaysian Palm Oil Board (MPOB), No. 6, Persiaran Institut, Bandar Baru Bangi, 43000 Kajang, Selangor, Malaysia

\begin{abstract}
Ganoderma boninense is a causal agent of basal stem rot (BSR) and is responsible for a significant portion of oil palm (Elaeis guineensis) losses, which can reach US\$500 million a year in Southeast Asia. At the early stage of this disease, infected palms are symptomless, which imposes difficulties in detecting the disease. In spite of the availability of tissue and DNA sampling techniques, there is a particular need for replacing costly field data collection methods for detecting Ganoderma in its early stage with a technique derived from spectroscopic and imagery data. Therefore, this study was carried out to apply the artificial neural network (ANN) analysis technique for discriminating and classifying fungal infections in oil palm trees at an early stage using raw, first, and second derivative spectroradiometer datasets.

These were acquired from 1,016 spectral signatures of foliar samples in four disease levels (T1: healthy, T2: mildly-infected, T3: moderately infected, and T4: severely infected). Most of the satisfactory results occurred in the visible range, especially in the green wavelength. The healthy oil palms and those which were infected by Ganoderma at an early stage (T2) were classified satisfactorily with an accuracy of $83.3 \%$, and $100.0 \%$ in 540 to $550 \mathrm{~nm}$, respectively, by ANN using first derivative spectral data. The results further indicated that the sensitive frond number modeled by ANN provided the highest accuracy of $100.0 \%$ for frond number 9 compared with frond 17 . This study showed evidence that employment of ANN can predict the early infection of BSR disease on oil palm with a high degree of accuracy.
\end{abstract}

The yield loss inflicted on oil palm production due to Ganoderma boninense has been estimated to cost producers as much as US\$500 million a year. G. boninense has been identified as a major pathogen that threatens the production of palm oil through basal stem rot (BSR) disease. The disease is not only one of the major pathological problems among fungal diseases of oil palm, but it is also the most destructive disease affecting plantations in Southeast Asia.

BSR identification is very difficult because the disease is symptomless at the early stage of infection. Symptoms of infection are usually manifested when it has already reached a critical stage, thus imposing challenges on effective disease management. Several foliage symptoms that can represent the infection of BSR are decaying of the bottom of the stem where basidiocarps develop. Stem decaying limits the uptake of water and supplements from the root, making chlorosis and yellowing as indicators of loss of leaf pigments. When the disease is at the advanced stage, more fronds shrivel and hang down to a skirt structure (Turner and Gillbanks 1974). Another noticeable indication is the flattening of the crown and unopened spears. In the majority of extreme cases, those stems may be significantly crack.

While there is not yet an effective treatment for BSR, nonetheless, early detection of infected palms is undeniably essential for economical infection management. Nowadays, the identification of BSR is performed according to various methods. For example, (i) colorimetric method using ethylenediaminetetraacetic acid (EDTA) (Natarajan et al. 1986), (ii) Ganoderma-selective media (GSM) (Ariffin and Idris 1992), (iii) polyclonal immunizer (PAb) (Darmono 2000), (iv) polymerase bind response (PCR) (Idris et al. 2003), and (v) electronicnose (e-nose) devices (Abdullah et al. 2011; Markom et al. 2009). Nonetheless, these aforementioned techniques are time-consuming

Corresponding author: Farrah Melissa Muharam;

E-mail: farrahm@upm.edu.my.

Accepted for publication 2 February 2017.

(C) 2017 The American Phytopathological Society detection methods, expensive and impractical for large plantation areas. An ideal system for identification of infections requires precise preparation, speed, and includes nondestructive methods.

Optical remote sensing, especially those acquired using hyperspectral sensors, is widely used due to the changes in spectral reflectance in plants that are well associated with varying degrees and types of stress (Alexander et al. 2014; Balasundaram et al. 2009; Dayou et al. 2014; Liu et al. 2007; Naidu et al. 2009; Tawfik et al. 2013; West et al. 2003; Yang et al. 2009; Zhang et al. 2012). Healthy plants commonly exhibit significantly lower spectral reflectance in the visible range (400 to $700 \mathrm{~nm}$ ), while unhealthy plants under different stresses show different spectral patterns due to changes in physiology and biochemistry in the leaves that are subject to stresses (Asrar 1989; Govender et al. 2009; Moran et al. 1997; Sanches et al. 2014). For assessing vegetation stress, advanced data mining analysis, such as principal component analysis (PCA) (Bauriegel et al. 2011; Harini and Bhaskari 2011; Liu et al. 2007; Thenkabail et al. 2004), support vector machine (SVM) (Karimi et al. 2006; Pourreza et al. 2016; Rumpf et al. 2010), and artificial neural network (ANN) (Glezakos et al. 2010; Liu et al. 2010; Noh et al. 2006; Paul and Munkvold 2005; Wang et al. 2008) have been utilized, apart from methods such as spectral derivative analysis and vegetation indices. Pourreza et al. (2016) utilized SVM to explain differentiable wavelengths for identification of a fungal disease, namely citrus black spot (CBS) in citrus species with resulting overall accuracies of $94.6 \%$. The ability of combining vegetation indices and SVM for early detection of foliar sugar beet diseases caused by fungal pathogen Cercospora beticola (Sacc) was demonstrated by Rumpf et al. (2010). The results obtained from their study showed the classification accuracies between healthy sugar beet leaves and diseased leaves of up to 97\%. Additionally, Harini and Bhaskari (2011) successfully identified diseased tomato leaves by developing a detection system based on wavelets and PCA. The mechanism was proven to be effective for disease detection with an accuracy of $90.0 \%$.

In Ganoderma, early detection studies like that of Shafri and Anuar (2008) identified sensitive wavelengths to different Ganoderma damage types with using raw, first, and second derivative spectra. They 
encountered a challenge to spectrally discriminate mildly infected oil palms from the healthy ones due to the overlapping spectral responses of these two infection classes. In another study, Shafri et al. (2011) carried out a maximum likelihood classifier to assess the optimal subset of hyperspectral wavebands with and without Ganoderma infection between 6-month-old seedlings. This study offered 24 most sensitive wavelengths that are located in the green and red regions, although $82.0 \%$ accuracy was obtained by the classification.

Lelong et al. (2010) used raw and first derivative canopy spectral data obtained from a spectroradiometer to detect the existence of spectral differences in oil palms exhibiting three Ganoderma damage levels. The results displayed the efficiency of red-edge reflectance (from 680 to $730 \mathrm{~nm}$ ) to indicate significant differences between healthy and infected oil palms with up to $98.0 \%$ overall accuracy, including severely infected palms. Nevertheless, considerably more work needs to be done for early detection because the model has not yet been able to discriminate between healthy and presymptomatic palms. In a study by Liaghat et al. (2014), the KNN based model could differentiate between healthy and slightly damaged palms with a high classification accuracy of $92.0 \%$ at the 325 to $1,075 \mathrm{~nm}$ wavelength using a second derivative of spectral dataset and principal component analysis (PCA). The results are in accord with recent studies indicating that the spectral based classification approach has important implications for disease management of oil palm, chiefly the fatal Ganoderma infection.

As stated earlier, previous studies were able to present high discrimination accuracy between healthy and moderately infected samples (Liaghat et al. 2014; Shafri et al. 2011). However, the focus of this research is on mild or early stage infection where there is no visible symptom of infection that has yet appeared. This study was carried out to determine the capability of artificial neural networks (ANN) to detect different $G$. boninense damage levels in oil palm. Presently, ANN has become an accepted method for agricultural researchers because of its ability to predict, forecast, and classify biologically related phenomena. The main advantage of neural networks for disease modeling is that the model is developed prior to assumption of the model form itself, unlike the regression method. The former has the ability to produce more consistent predictions rather than the latter; while the ANN is more time consuming, it allows consideration of multiple factors into the modeling, and models with higher order interactions among the multiple factors using shared hidden network. ANN was proven beneficial to investigate the dynamic relationship between many variables, especially for plant disease and stress detection (Glezakos et al. 2010; Noh et al. 2006; Paul and Munkvold 2005; Wang et al. 2008).

The objective of this study, therefore, was to evaluate the effectiveness of raw and derivative reflectance in the visible and near-infrared regions analyzed with ANN to detect BSR presence at early stage of infection.

Table 1. Ganoderma severity levels based on visual symptoms and Ganoderma-selective media (GSM) test for oil palms

\begin{tabular}{ll}
\hline Severity level & \multicolumn{1}{c}{ Symptoms } \\
\hline T1 (healthy) & $\begin{array}{l}\text { Negative GSM }{ }^{\mathrm{a}} \text { test } \\
\text { Healthy leaves and normal palm canopy }\end{array}$ \\
T2 (mild) & $\begin{array}{l}\text { Positive GSM test } \\
\text { Presence of mycelium in the stem bark, or brittle wood }\end{array}$ \\
& $\begin{array}{l}\text { Healthy leaves and normal palm canopy } \\
\text { T3 (moderate) }\end{array}$ \\
& $\begin{array}{l}\text { Positive GSM test } \\
\text { Presence of mycelium in the stem bark, and fruiting body }\end{array}$ \\
T4 (severe) & $\begin{array}{l}\text { Less than 50\% foliar symptoms } \\
\text { Presence of fruiting body at the bottom of the rotten stem }\end{array}$ \\
& More than 50\% foliar symptoms
\end{tabular}

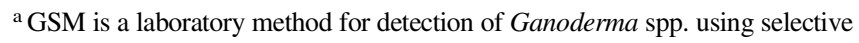
media. The method involves placing the suspected oil palm tissues (stem part) onto GSM in Petri dishes. GSM was prepared as described by Ariffin and Idris (1992). The GSM consists two parts; part A and B, which contains antibiotics (streptomycin sulfate and chloramphenicol) and fungicides (pentachloronitrobenzene [PCNB], Ridomil, and Benlate) to avoid the growth of unwanted bacteria and fungi but to allow Ganoderma spp. to grow.

\section{Materials and Methods}

Study sites. The study was conducted in an oil palm estate, cv. Tenera, owned by United Malacca Berhad, located in Machap subdistrict, Melaka, Malaysia $\left(2.402^{\circ} \mathrm{N}, 102.327^{\circ} \mathrm{E}\right)$, which was previously cultivated with rubber. The field of study was 12 -year-old mature oil palm planted in 2002. It is a second generation oil palm that receives standard plantation practices; however, the examined field did not receive any fungicide treatment.

Ganoderma severity trial. During field data collections conducted in February 2014 (first trial) and October 2014 (second trial), we identified and marked 374 palms in the aforementioned field with four stages of Ganoderma symptoms adopted from Lelong et al. (2010) (Table 1). To confirm the presence of Ganoderma-related fungus, the GSM test was conducted on palms with an absence of the Ganoderma fruiting body. Trunk samples were acquired from trunk drilling and sent for laboratory analysis. Based on both visual symptoms and GSM test results, the samples were segregated into four classes designated as T1 (healthy), T2 (mildly infected or early stage), T3 (moderately infected), and T4 (severely infected) (Fig. 1). The main difference between the mild severity level in this study and others is that in our study the mildly infected oil palms showed no symptoms and their disease level can only be confirmed by GSM test, whereas the mildly infected palms in other studies have some symptoms of infection such as pale and rotten leaves, poor canopy, and unopened spears.

Spectra acquisition. During our first trial, 144 of T1, 64 of T2, 128 of T3, and 80 of T4 foliar samples from both frond numbers 9 and 17 were collected for the spectral measurement. During the second trial, 160 of T1, 160 of T2, 160 of T3, and 120 of T4 foliar samples were gathered. The reasons for different foliar samples per disease level was due to rotting and wilting of frond number 17 of the severely infected palms.

VIS-NIR spectral reflectance data were measured at a $1.45 \mathrm{~nm}$ interval with a resolution of $5 \mathrm{~nm}$ in the range of 273 to $1,100 \mathrm{~nm}$ used a portable spectroradiometer GER model 1500 (Geophysical and Environmental Research Corporation, Millbrook, NY) (571 spectral bands) with an $8^{\circ}$ field of view (FOV) at the integration time of $5 \mathrm{~ms}$ and up. Field data collection was performed $2 \mathrm{~h}$ before and after local solar noon to measure the target-specific spectral response under natural illumination conditions.

Spectral reflectance data were collected from two right and left leaflets of fronds 9 and 17 of each of the selected palms, resulting in 16 replicate measurements for each palm. The observations were made immediately after the leaflets were detached from their fronds. The spectral measurement was conducted at the leaf level, with the observation being taken using a fiber optic cable at a close distance from the leaf surface. Prior to each set of observations, a white background reference panel was performed to calibrate the instrument with respect to variations in incident light intensity and solar radiation. The percentage of reflectance from the target leaves was computed by dividing the reflected radiance with the incident radiation. Finally, the mean reflectance of each frond for each tree in the given GER spectral region was calculated.

Weather station. Weather monitoring systems have been used to observe any change in weather parameters that could contribute to plant diseases, including Ganoderma disease in oil palm. Weather data analysis was made by a WatchDog weather station Model 2000 (Spectrum Technologies, Inc., U.S.A.) located inside the experimental field throughout the study period. The weather station provided data on temperature $\left( \pm 0.6^{\circ} \mathrm{C}\right)$, rainfall $( \pm 2 \%)$, and relative humidity $( \pm 3 \%)$. Disease severity levels and weather data were monitored at the study sites; hence, the effect of temperature, rainfall, and relative humidity were considered to improve understanding the relationship between weather data and severity levels of Ganoderma.

Data analysis. In this study, the differentiations of Ganoderma severity levels were determined by analyzing specific spectral signatures at different disease severities and different frond numbers. Raw, first, and second derivative dataset have been used in this research. Derivative data were calculated by division of the differences between spectral reflectance derived at one wavelength with spectral 
reflectance of its consecutive wavelength by the differences between those two wavelengths (Demetriades-Shah et al. 1990). The same procedure was used to derive the second derivative reflectance.

Artificial neural networks analysis. The neural network chosen in this study was multilayer and back-propagation (BP) due to the ability to learn and determine nonlinear combinations. The architecture of neural network may consist of an input layer, $x_{i}$, where $i=1$ to $n$, a hidden layer, $t_{i}$, and an output layer, $o_{j}$, where $j=1$ to $m$ (Fig. 2). The input layer represents independent variables of interest, the hidden layer generates the relationship between the input and output layers, and the output layer characterizes dependent variables of interest. The input and hidden layers are interconnected with weight, $w_{i}$. In each training set where the inputs are being feedforward to a network, the weight of each input, $w_{i}$, and collective weights of different input combinations that is actually a sigmoidal weighted value, $t_{i}$, will be dictated. From this single training, estimated output value, $o_{j}$ will be derived from a transfer function based on the $t_{i}$, or known as $f$. The estimated values will be compared with the actual output values, resulting in an error term. The error will be back propagated to the network and used to adjust the error term until the minimum error is achieved. The training is therefore an iterative procedure. Once the iteration stops, the final training set will be used to classify the inputs into their ANN-determined output classes. Detailed explanations on the working principle of ANN can be found in McClelland (2015).

As the network contained numerous interacting nonlinear neurons in various layers, it could catch moderately complex phenomena.

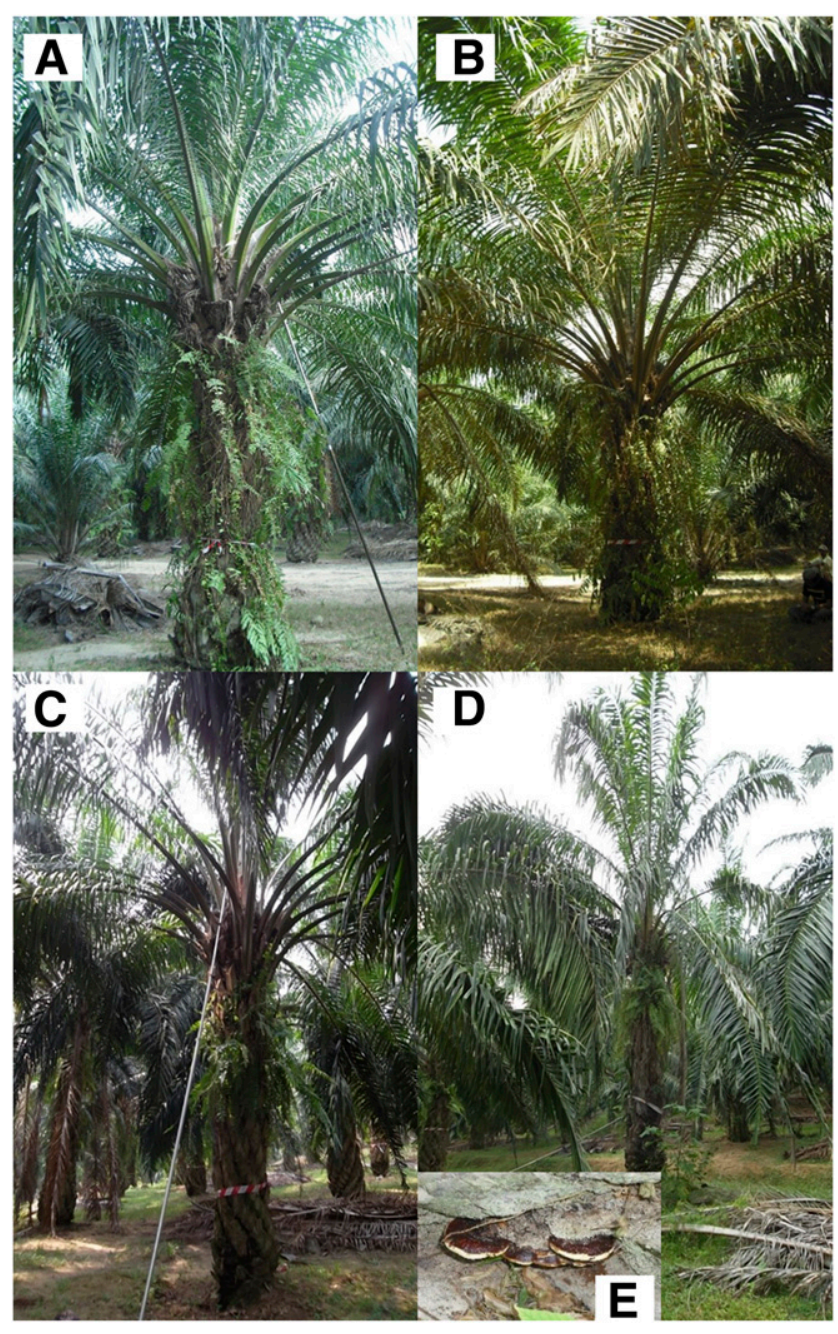

Fig. 1. (A) Healthy, and Ganoderma infected oil palms at different severity levels: (B) mild (T2), (C) moderate (T3), and (D) severe (T4), including (E) presence of fruiting body at the bottom of rotten stem. The palms were sampled in February 2014 in an oil palm plantation of cv. Tenera belonging to United Malacca Berhad, in Machap, Melaka, Malaysia.
Various ANN architectures were applied to the data sets to verify the proficiency of various combinations of input variables, learning optimization methods and different numbers of neurons on the hidden layer by MATLAB 2014a software. Our architectures were defined by one input layer (either raw or derivative datasets of different severity levels), one output layer (severity levels), and two hidden nodes, and also trained for 1,000 epochs utilizing a range of wavelength bands. The first ANN architecture was developed with 3-2-2 and 4-2-2 topology using three or four individual wavelengths between 540 and $650 \mathrm{~nm}$ as input nodes. The second architecture was based on range of raw wavelengths as input nodes. For this purpose, the wavelengths used have either a $10 \mathrm{~nm}$ range $(540$ to $550 \mathrm{~nm}, 550$ to 560,560 to $570 \mathrm{~nm}, 570$ to $580 \mathrm{~nm}$, and 580 to $590 \mathrm{~nm}), 30 \mathrm{~nm}$ range $(680$ to $710 \mathrm{~nm}), 90 \mathrm{~nm}$ range $(710$ to $800 \mathrm{~nm}$ ), or $130 \mathrm{~nm}$ range (650 to $780 \mathrm{~nm}$ ). According to the number of the input nodes, the network configurations were 10-2-2, 30-2-2, 90-2-2, or 130-2-2, respectively. The second architecture was then repeated for the FDR and SDR datasets. For these architectures, two output nodes were assigned: zero was for healthy (T1) and one was for mildly infected oil palm (T2). Both of these architectures were tested to find the best wavelength combinations on a seasonal and frond basis.

The network ran in two steps, training and testing, in a randomly grouped data set. During the training process, the input gradients were computed, the input and the desired output patterns were formed, the network weights and biases were updated, and finally the learning process of ANN was carried out in order to produce a trained network. Consequently, during the testing process, the trained networks were validated in order to assess the most highly accurate model. If the validation of a trained network produced unacceptable accuracy, the training and testing procedures would be repeated in an iterative procedure. In this study, $70.0 \%$ of data were assigned for the purpose of training

$$
t_{i}=\sum_{i=1}^{n} w_{i} x_{i}
$$



Input Layer

Hidden layer

Output Layer

Fig. 2. The structure of the neurons in the artificial neural network (ANN) used in this study. The $x_{i}$ is input layers while $t_{i}$ is hidden layers, where in both layers $i=1$ to $n$, and $o_{j}$ is output layers where $j=1$ to $m$. The $w_{i}$ or weight interconnects the input and hidden layers while $t_{i}$ is the sigmoidal function of collective weights of different input combinations. The $f$ is a transfer function based on the $t_{i}$ that estimates output value, $o_{i}$. 
the network, while the remaining $30.0 \%$ of data were allocated for testing model accuracy.

Because the aim of the research was to distinguish between two initial severity levels, 1 and 0 was assigned for mildly infected and healthy oil palms, respectively, in order to digitize the training output data. The training process was stopped once the network reached the error threshold or maximum number of training epochs. More than 600 programs that were run for both fronds were carried out to determine the best discriminant wavelengths.

\section{Results}

Ganoderma severity trial. During the first trial conducted in February 2014, 374 surveyed oil palms were labeled as T1 (213), T2 (9), T3 (9), and T4 (12). However, during the second trial performed in October 2014, the numbers changed to 213 (T1), 16 (T2), 17 (T3), and 12 (T4) due to progression of the disease over time and changes in weather conditions.

Weather data. According to the data collected from the weather station, it is clear that the first and second trials were characterized by dry and rainy seasons, respectively. The relative humidity of the first trial period was much drier than the second trial (Fig. 3), where the readings captured in the first 3 weeks in February fluctuated around 60.0 to $80.0 \%$ and began to drop to below $50.0 \%$. On the other hand, the relative humidity for October stayed above $70.0 \%$ throughout the month. Despite of the fluctuation in relative humidity and rainfall during the two trials, the relative humidity increased by approximately $30.0 \%$ during the second trial. The lowest and highest average temperatures during the first and second trials were 20.2 and $35.1^{\circ} \mathrm{C}$, respectively. The cumulative precipitation of the second trial was $148.7 \mathrm{~mm}$, compared with $60.7 \mathrm{~mm}$ in the first trial, as is evident in Figure 2.

Spectral signatures. For each trial, 1,016 spectral signatures were acquired from infected (T2, T3, T4) and noninfected (T1) oil palms. For both fronds and trials, the spectral differences between healthy and infected signatures in raw data were noted visually in the 520 to $580 \mathrm{~nm}$ range (Fig. $4 \mathrm{a}, \mathrm{b}, \mathrm{e}, \mathrm{f}$ ), and the 800 to $900 \mathrm{~nm}$ range (Fig. 4c, d, g, h).

Regardless of frond numbers and trial, the spectral curves of healthy oil palm were characterized by lower reflectance in the visible region (500 to $600 \mathrm{~nm}$ ) and higher reflectance in the NIR ranges (800 to $900 \mathrm{~nm}$ ) than those at an early stage, with an exception for frond 9 of the second trial. It is worth noting that spectral signatures of the second trial approximately followed the same trend as the first trial. However, acquired signatures of frond number 9 showed better visual discrimination compared with frond number 17 because the healthy fronds have a lower reflectance in the visible range and can easily be differentiated from other palms being infected.

Artificial neural network. Table 2 shows the best four combinations of wavelengths for the 3-2-2 or 4-2-2 architecture for the first and second trial. Based on the first trial result, we concluded that the wavelengths that have the highest overall accuracy $(52.7 \%)$, which were 553, 555, and $556 \mathrm{~nm}$, could detect healthy oil palm with $56.7 \%$ and mildly infected oil palm with $48.6 \%$ accuracy. The best result for the individual raw wavelength was acquired from 553, 557, and $562 \mathrm{~nm}$ from the second trial using a 3-2-2 topology with $83.3 \%$ overall accuracy. Healthy oil palm could be distinguished with $66.7 \%$ accuracy, while the accuracy of infected palms was $100.0 \%$.

Table 3 depicts that the best results of raw data were provided by the 550 to $560 \mathrm{~nm}$ range of the second trial, with an accuracy of $66.7 \%$ for healthy and $100.0 \%$ for infected palms and $83.3 \%$ for overall accuracy. For the first trial, the overall accuracies were almost the same, which were around 66.0 to $69.0 \%$ in all the wavelength ranges. The best result of the first trial belonged to 560 to $570 \mathrm{~nm}$, though the overall accuracy was not very high in comparison with the second. However, this range showed satisfying results without necessarily using any preprocessing of spectral data.

The FDR analysis of the second trial showed a $100.0 \%$ success rate in detecting BSR within 550 to $560 \mathrm{~nm}$ and 650 to $780 \mathrm{~nm}$, although the overall success rate decreased to 91.7 and $75.0 \%$, respectively (Table 4). However, proper prediction of healthy palms could be done with more than $80.0 \%$ accuracy only with the 550 to $560 \mathrm{~nm}$ range. The most useful SDR spectra for detecting mildly infected palms were noticed at 540 to $550 \mathrm{~nm}, 570$ to $580 \mathrm{~nm}, 650$ to $780 \mathrm{~nm}$, and 680 to $710 \mathrm{~nm}$ of the second trial (Table 5). However, the accuracy of the healthy pair of 570 to $580 \mathrm{~nm}, 650$ to $780 \mathrm{~nm}$, and 680 to $710 \mathrm{~nm}$ was only $66.7 \%$. The best overall accuracy in first and second trial was gained from 540 to $550 \mathrm{~nm}$ and 650 to $780 \mathrm{~nm}$ by $83.3 \%$.

The results and analyses of the first data collection showed that the overall accuracy of most of the wavelength ranges were not satisfactory because the figures were less than $70.0 \%$ (Table 2 to 5). However, $70.3 \%$ overall prediction accuracy was acquired from the 550 to $560 \mathrm{~nm}$ range using the FDR. The healthy and infected palms were recognized by the model with $83.8 \%$ and $56.8 \%$ accuracy, respectively.

Regarding the best results obtained using different frond numbers, the classification accuracy among two severity levels of Ganoderma was tested (Table 6). The discrimination analyses from different datasets demonstrated that by using frond 9 and either raw reflectance at 553,557 , and $562 \mathrm{~nm}$ or the first derivative dataset in the range of 550 to $560 \mathrm{~nm}$, we could perfectly predict not only the infection at the early stage, but also for the healthy palms. Furthermore, by using frond 17 and SDR of 540 to $550 \mathrm{~nm}$ dataset, a similar accuracy could be achieved.

\section{Discussion}

The current research study was to evaluate the application of leaf spectral data analyzed using ANN to detect BSR disease early by selecting the best band as a practical model. This paper also discusses
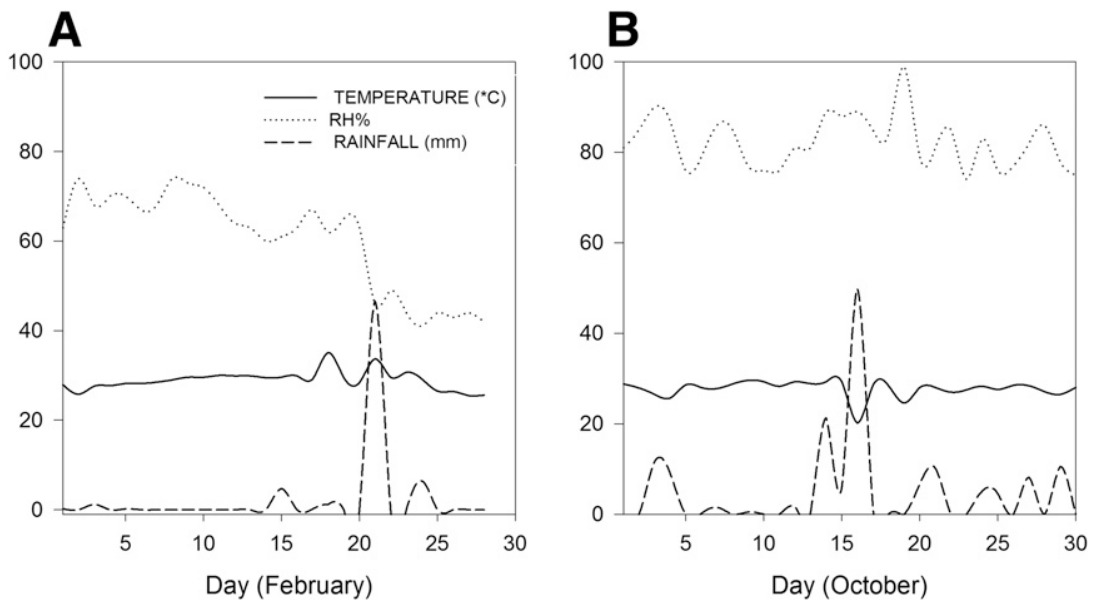

Fig. 3. Mean of daily air temperature $\left({ }^{\circ} \mathrm{C}\right)$, relative humidity $(\%)$, and rainfall $(\mathrm{mm})$ acquired from installed weather stations in the study area which was an oil palm plantation with different levels of Ganoderma infected oil palms during $(\mathbf{A})$ the first trial (February) and (B) the second trial (October). 
the efficacy and usefulness of spectral data-ANN model against the results of other methods like PCR, DNA-based, and e-nose devices.

Although the PCR method so far provides the most reliable detection, this method has some drawbacks, such as being sensitive to direct or carry-over contamination (Corless et al. 2000) in addition to many sample collections needing to be done to eradicate amplification inhibitors. Methods such as the colorimetric method and DNA-based model can be used as a robust detection tool, but they are not very practical at the asymptomatic stage under field conditions, especially at large plantations, because they are time-consuming, labor-intensive, and
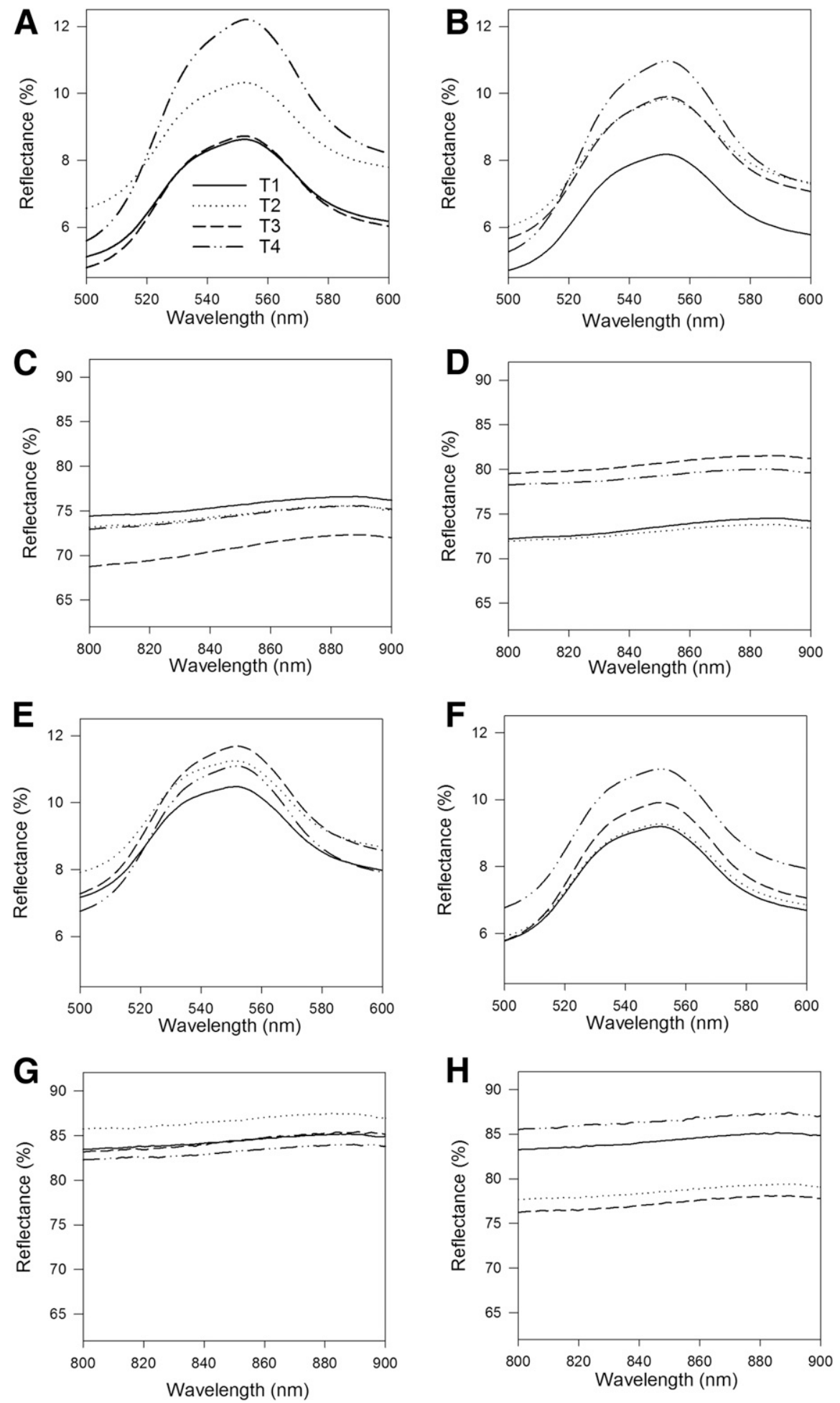

Fig. 4. Acquired spectral signatures from (A) visible region (500 to $600 \mathrm{~nm}$ ) of frond 9 during the first trial, (B) visible region (500 to $600 \mathrm{~nm})$ of frond 17 during the first trial, (C) near infra-red (NIR) region (800 to $900 \mathrm{~nm}$ ) of frond 9 during the first trial, (D) NIR region (800 to $900 \mathrm{~nm}$ ) of frond 17 during the first trial, (E) visible region (500 to $600 \mathrm{~nm})$ of frond 9 during the second trial, $(\mathbf{F})$ visible region $(500$ to $600 \mathrm{~nm}$ ) of frond 17 during the second trial, $(\mathbf{G})$ NIR region $(800$ to $900 \mathrm{~nm})$ of frond 9 during the second trial, and $(\mathbf{H})$ NIR region $(800$ to $900 \mathrm{~nm}$ ) of frond 17 during the second trial. The spectral signatures were obtained from a GER 1500 spectroradiometer from different numbers of foliar samples as follows: Frond 9: 72 of T1, 32 of T2, 64 of T3, and 40 T4 during the first trial, and 80 of T1, 80 of T2, 80 of T3, and 80 of T4 during the second trial. Frond 17: 72 of T1, 32 of T2, 64 of T3, and 40 of T4 during the first trial, and 80 of T1, 80 of T2, 80 of T3, and 40 of T4 during the second trial. T1 represents healthy palms, T2 represents mildly Ganoderma infected oil palms, T3 represents moderately Ganoderma infected oil palms, and T4 represents severely Ganoderma infected oil palms. 
expensive. In other techniques like the e-nose, skilled operators should consider all external disease symptoms of each tree in order to differentiate between healthy and unhealthy oil palm in addition to involving a complex gas mixture in the analysis. On a special note, while this method cannot justify the detection of BSR as definite as the PCR method, the spectral analysis is appropriate for mass screening to detect Ganoderma under field conditions, considering that oil palm is commonly cultivated in large plantation areas.

While other factors such as biotic stress, nutritional deficiency, and other pathogens could also cause the loss of chlorophyll, in most cases, the association between reflectance variations with the Ganoderma infection could be ambiguous. Since BSR disease and nitrogen (N) deficiency symptoms could co-occur within the same oil palm trees, $\mathrm{N}$ content could be used as the benchmark. Nitrogen contents of various severity levels in this study were found to be statistically insignificantly different (2.0 to $2.5 \%$ ). While there is no solid evidence to show the separability between BSR disease and $\mathrm{N}$ content based on reflectance spectroscopy, it can be suggested that 550 to $560 \mathrm{~nm}$ were selected as sensitive bands to BSR because the $\mathrm{N}$ contents of $\mathrm{T} 1$ and $\mathrm{T} 2$ were insignificantly different.

Literature have shown that variations of leaf reflectance under $\mathrm{N}$-stressed and disease-stressed conditions could be observed at different wavelengths. Zhao et al. (2005) found that $\mathrm{N}$-deficit stress on wheat increased leaf reflectance at $555 \mathrm{~nm}$ and $715 \mathrm{~nm}$ and caused a red-edge point to the shorter wavelength, while Ashourloo et al. (2014) reported that spectral characteristics of wheat at various levels of $P$. triticina infestation were varied at wavelengths of 605,695 , and $455 \mathrm{~nm}$. On the other hand, for rice, Yang et al. (2009) indicated that changes in reflectance spectrum of N-stressed rice occurred at $1,376 \mathrm{~nm}$, while Di et al. (2009) indicated that different levels of rice panicle blast could be differentiated at six different effective wavelengths; 459, 546, 569, 590, 775 , and $981 \mathrm{~nm}$.

Table 2. Network configurations and performance of artificial neural network (ANN) for discriminating between healthy and Ganoderma mildly infected oil palms using individual wavelengths acquired from a GER spectroradiometer

\begin{tabular}{|c|c|c|c|c|c|}
\hline \multirow[b]{2}{*}{ Trial } & \multirow[b]{2}{*}{ Range of wavelengths (nm) } & \multirow[b]{2}{*}{ Network configurations } & \multicolumn{3}{|c|}{ Discrimination accuracy ${ }^{\mathbf{a}}(\%)$} \\
\hline & & & Healthy (T1) & Mildly infected (T2) & $\overline{\text { Overall }}$ \\
\hline \multirow[t]{4}{*}{ First trial } & $553,555,556$ & $3-2-2$ & 56.7 & 48.6 & 52.7 \\
\hline & $556,558,559$ & $3-2-2$ & 43.2 & 56.7 & 50.0 \\
\hline & $545,548,552,561$ & $4-2-2$ & 45.4 & 56.5 & 51.3 \\
\hline & $540,550,559$ & $3-2-2$ & 56.3 & 47.4 & 51.7 \\
\hline \multirow[t]{4}{*}{ Second trial } & $553,557,562$ & $3-2-2$ & 66.7 & 100.0 & 83.3 \\
\hline & $552,561,570$ & $3-2-2$ & 33.0 & 66.7 & 66.7 \\
\hline & $545,548,552,561$ & $4-2-2$ & 84.0 & 78.5 & 78.5 \\
\hline & $540,550,560$ & $3-2-2$ & 61.0 & 70.0 & 70.0 \\
\hline
\end{tabular}

${ }^{\text {a }}$ The accuracies were derived for 39 spectral leaf measurements of T1 and 19 spectral leaf measurements of T2 during the first trial, and 48 spectral leaf measurements of $\mathrm{T} 1$ and 48 spectral leaf measurements of $\mathrm{T} 2$ during the second trial.

Table 3. Network configurations and performance of artificial neural network (ANN) for discriminating between healthy and Ganoderma mildly infected oil palms using range of raw wavelengths acquired from a GER spectroradiometer

\begin{tabular}{|c|c|c|c|c|c|c|c|c|}
\hline \multirow{3}{*}{$\begin{array}{l}\text { Program } \\
\text { number }\end{array}$} & \multirow{3}{*}{$\begin{array}{c}\text { Range of } \\
\text { wavelength }(\mathrm{nm})\end{array}$} & \multirow{3}{*}{$\begin{array}{c}\text { Network } \\
\text { configurations }\end{array}$} & \multicolumn{6}{|c|}{ Discrimination accuracy ${ }^{\mathrm{a}}(\%)$} \\
\hline & & & \multicolumn{3}{|c|}{ First trial } & \multicolumn{3}{|c|}{ Second trial } \\
\hline & & & Healthy (T1) & Mildly infected (T2) & Overall & Healthy (T1) & Mildly infected (T2) & Overall \\
\hline 1 & 540 to 550 & $10-2-2$ & 64.8 & 67.5 & 66.2 & 66.7 & 66.7 & 66.7 \\
\hline 2 & 550 to 560 & $10-2-2$ & 62.2 & 70.2 & 66.2 & 66.7 & 100.0 & 83.3 \\
\hline 3 & 560 to 570 & $10-2-2$ & 70.2 & 67.5 & 68.9 & 33.0 & 66.7 & 50.0 \\
\hline 4 & 570 to 580 & $10-2-2$ & 72.9 & 64.8 & 68.9 & 66.7 & 58.3 & 62.5 \\
\hline 5 & 580 to 590 & $10-2-2$ & 67.5 & 67.5 & 67.5 & 58.8 & 58.8 & 58.8 \\
\hline 6 & 650 to 780 & $130-2-2$ & 50.0 & 53.0 & 51.5 & 40.4 & 51.5 & 45.9 \\
\hline 7 & 680 to 710 & $30-2-2$ & 45.8 & 39.6 & 42.7 & 48.9 & 52.3 & 50.6 \\
\hline 8 & 710 to 800 & $90-2-2$ & 53.4 & 37.0 & 45.2 & 56.0 & 43.3 & 49.6 \\
\hline
\end{tabular}

${ }^{a}$ The accuracies were derived for 39 spectral leaf measurements of T1 and 19 spectral leaf measurements of T2 during the first trial, and 48 spectral leaf measurements of $\mathrm{T} 1$ and 48 spectral leaf measurements of $\mathrm{T} 2$ during the second trial.

Table 4. Network configurations and performance of Artificial Neural Network (ANN) for discriminating between healthy and Ganoderma mildly infected oil palms using range of first derivative dataset (FDR) wavelengths acquired from a GER spectroradiometer

\begin{tabular}{|c|c|c|c|c|c|c|c|c|}
\hline \multirow{3}{*}{$\begin{array}{l}\text { Program } \\
\text { number }\end{array}$} & \multirow{3}{*}{$\begin{array}{c}\text { Range of } \\
\text { wavelength }(\mathrm{nm})\end{array}$} & \multirow{3}{*}{$\begin{array}{c}\text { Network } \\
\text { configurations }\end{array}$} & \multicolumn{6}{|c|}{ Discrimination accuracy ${ }^{\mathrm{a}}(\%)$} \\
\hline & & & \multicolumn{3}{|c|}{ First trial } & \multicolumn{3}{|c|}{ Second trial } \\
\hline & & & Healthy (T1) & Mildly infected (T2) & Overall & Healthy (T1) & Mildly infected (T2) & Overall \\
\hline 1 & 540 to 550 & $10-2-2$ & 62.2 & 37.8 & 50.0 & 66.7 & 66.7 & 66.7 \\
\hline 2 & 550 to 560 & $10-2-2$ & 83.8 & 56.8 & 70.3 & 83.3 & 100.0 & 91.7 \\
\hline 3 & 560 to 570 & $10-2-2$ & 59.5 & 59.5 & 59.5 & 50.0 & 83.3 & 66.0 \\
\hline 4 & 570 to 580 & $10-2-2$ & 62.2 & 48.6 & 55.4 & 83.3 & 66.7 & 75.0 \\
\hline 5 & 580 to 590 & $10-2-2$ & 62.2 & 48.6 & 56.8 & 50.0 & 66.0 & 58.3 \\
\hline 6 & 650 to 780 & $130-2-2$ & 75.6 & 51.3 & 63.5 & 50.0 & 100.0 & 75.0 \\
\hline 7 & 680 to 710 & $30-2-2$ & 67.5 & 27.0 & 47.2 & 66.7 & 83.3 & 75.0 \\
\hline 8 & 710 to 800 & $90-2-2$ & 53.4 & 37.0 & 45.2 & 66.0 & 33.0 & 50.0 \\
\hline
\end{tabular}

${ }^{\text {a }}$ The accuracies were derived for 39 spectral leaf measurements of T1 and 19 spectral leaf measurements of T2 during the first trial, and 48 spectral leaf measurements of $\mathrm{T} 1$ and 48 spectral leaf measurements of $\mathrm{T} 2$ during the second trial. 
This study provided evidence for usefulness of reflectance spectroscopy and ANN for detecting Ganoderma infection in oil palm at its early stage of growth. A neural network was employed to detect mildly infected Ganoderma by analyzing the raw, FDR, and SDR spectral data. The results confirmed that the ANN has the capability to identify the presence of dynamic relationships that exist between the variables tested in this study, which were spectral reflectance at many wavelengths and levels of Ganoderma infection.

By using raw individual spectra at 553,557 , and $562 \mathrm{~nm}$ or wavelength range from 550 to $560 \mathrm{~nm}$, it was possible to obtain $100.0 \%$ classification accuracy for mildly infected palms that were not yet manifesting visible symptoms. The results also confirmed that at contiguous wavelengths, prediction of mildly infected palms using FDR and SDR generally had the most satisfactory result using 550 to $560 \mathrm{~nm}$ and 650 to $780 \mathrm{~nm}$ spectrums. However, in comparing the overall performance of raw, FDR, and SDR datasets, the FDR was found to have the best overall accuracy with $91.7 \%$, which was $100.0 \%$ for T2 and $83.3 \%$ for T1. As observed, ANN showed better results and accuracies for infected palms compared with healthy ones; although healthy palms did not have Ganoderma and they seem to be healthy, they may have suffered from other diseases or nutrient deficiencies that influenced their spectral properties.

Regardless of trial and spectral transformation, the best discriminant wavelengths for detecting the presence of BSR disease was found in the green wavelength, particularly from 550 to $560 \mathrm{~nm}$, and rededge, which is around 650 to $780 \mathrm{~nm}$. This suggests that the loss of chlorophylls was the first spectral indicator of this disease. This finding was confirmed by Hushiarian et al. (2013) and Naher et al. (2011), who found that infected palms always suffered from chlorotic issues because the disease attacked the root system, which degraded the lignin component and restricted the absorbtion of water and nutrients to the fronds and reduced chlorophyll production. This result agreed with the findings by Delalieux et al. (2009) and Ayala-Silva and Beyl (2005), who mentioned that reduction in chlorophyll concentration increased reflectance in the visible range and caused a shift in the position of the red-edge toward shorter or longer wavelengths. This result, however, contradicts the findings of Shafri et al. (2011), who found that the infected palms demonstrated sensitivity in the red wavelength, which is easily saturated due to absorption by chlorophyll for photosynthesis (Rees 2001).

Results presented by Lelong et al. (2010) using canopy reflectance obtained from a spectroradiometer showed $89 \%$ accuracy for early detection of Ganoderma infected oil palms. Better accuracies were achieved in this study, perhaps due to pureness of leaf spectra in relation to biochemical properties of the palms, where in this case the leaf pigmentation, compared with the canopy level spectra that contained information related to canopy such as leaf orientation and arrangement, and varying leaf ages. While the result acquired by Liaghat et al. (2014) demonstrated $92 \%$ accuracy for early detection by using second derivative datasets from 325 to $1,075 \mathrm{~nm}$, this study showed that $100 \%$ accuracy was achievable using a raw, specific range of spectral data without necessarily using any preprocessing of spectral data.

This study also examined the applicability of data collection under different weather conditions. Comparisons were made between the first and second trial and demonstrated that there was a large difference between measurements taken under different weather conditions and that more Ganoderma infections occurred in the second trial or wet season. A possible explanation for this is that climatic conditions may strongly affect the accuracy of classification on the data collection. It is surely understood that climate conditions impact the everyday variability as well levels of spore condensation. High relative humidity and moisture can possibly increase BSR infection because the fungal germ tube will germinate when relative humidity is above $70.0 \%$. Also, it was reported that in more than $90.0 \%$ of the days from June to October, Ganoderma spores were available in the environment (Grinn-Gofroń and Strzelczak 2011).

The current study also provided new insight on the best frond number to be analyzed for early detection of Ganoderma infections. The analysis of frond number datasets depicted that younger fronds (number 9) have a better ability to detect infected oil palms than older ones (number 17). Investigation revealed that frond number 9 had better effects on classification accuracy due to its younger leaf. Hence, for application programs, frond number 9 is the best frond to use to detect the

Table 5. Network configurations and performance of artificial neural network (ANN) for discriminating between healthy and Ganoderma mildly infected oil palms using range of second derivative dataset (SDR) wavelengths acquired from a GER spectroradiometer

\begin{tabular}{|c|c|c|c|c|c|c|c|c|}
\hline \multirow{3}{*}{$\begin{array}{l}\text { Program } \\
\text { number }\end{array}$} & \multirow{3}{*}{$\begin{array}{c}\text { Range of } \\
\text { wavelengths (nm) }\end{array}$} & \multirow{3}{*}{$\begin{array}{c}\text { Network } \\
\text { configurations }\end{array}$} & \multicolumn{6}{|c|}{ Discrimination accuracy ${ }^{\mathrm{a}}(\%)$} \\
\hline & & & \multicolumn{3}{|c|}{ First trial } & \multicolumn{3}{|c|}{ Second trial } \\
\hline & & & Healthy (T1) & Mildly infected (T2) & Overall & Healthy (T1) & Mildly infected (T2) & Overall \\
\hline 1 & 540 to 550 & $10-2-2$ & 64.8 & 32.4 & 48.6 & 83.3 & 83.3 & 83.3 \\
\hline 2 & 550 to 560 & $10-2-2$ & 29.7 & 75.6 & 52.7 & 83.3 & 33.3 & 58.3 \\
\hline 3 & 560 to 570 & $10-2-2$ & 51.3 & 51.3 & 51.3 & 83.3 & 33.3 & 58.3 \\
\hline 4 & 570 to 580 & $10-2-2$ & 51.3 & 64.8 & 58.1 & 66.7 & 83.3 & 75.0 \\
\hline 5 & 580 to 590 & $10-2-2$ & 51.3 & 64.8 & 58.1 & 50.0 & 66.0 & 58.3 \\
\hline 6 & 650 to 780 & $130-2-2$ & 78.3 & 48.6 & 63.0 & 66.7 & 100.0 & 83.3 \\
\hline 7 & 680 to 710 & $30-2-2$ & 59.4 & 32.4 & 45.9 & 66.7 & 83.3 & 75.0 \\
\hline 8 & 710 to 800 & $90-2-2$ & 32.0 & 45.1 & 38.5 & 33.0 & 58.0 & 45.5 \\
\hline
\end{tabular}

${ }^{a}$ The accuracies were derived for 39 spectral leaf measurements of T1 and 19 spectral leaf measurements of T2 during the first trial, and 48 spectral leaf measurements of $\mathrm{T} 1$ and 48 spectral leaf measurements of $\mathrm{T} 2$ during the second trial.

Table 6. Artificial neural network (ANN) classification accuracy of fronds number 9 and 17 for discriminating between healthy and Ganoderma mildly infected oil palms based on the best network configurations in raw wavelengths, range of wavelengths, first derivative (FDR) wavelengths, and second derivative (SDR) wavelengths acquired from a GER spectroradiometer

\begin{tabular}{|c|c|c|c|c|c|c|c|}
\hline \multirow[b]{3}{*}{ Dataset } & \multirow[b]{3}{*}{ Wavelengths (nm) } & \multicolumn{6}{|c|}{ Discrimination accuracy ${ }^{\mathrm{a}}(\%)$} \\
\hline & & \multicolumn{3}{|c|}{ Frond 9} & \multicolumn{3}{|c|}{ Frond 17} \\
\hline & & Healthy (T1) & Mildly infected (T2) & $\overline{\text { Overall }}$ & Healthy (T1) & Mildly infected (T2) & Overall \\
\hline RAW & $553,557,562$ & 100.0 & 100.0 & 100.0 & 80.0 & 85.0 & 82.8 \\
\hline RAW & 550 to 560 & 66.7 & 100.0 & 83.3 & 66.7 & 100.0 & 83.3 \\
\hline FDR & 550 to 560 & 100.0 & 100.0 & 100.0 & 100.0 & 66.7 & 83.3 \\
\hline SDR & 540 to 550 & 66.7 & 66.7 & 66.7 & 100.0 & 100.0 & 100.0 \\
\hline
\end{tabular}

${ }^{a}$ The accuracies were derived for 46 spectral leaf measurements of $\mathrm{T} 1$ and 46 spectral leaf measurements of $\mathrm{T} 2$ for each frond number. 
incidence of the disease because only measurement from a single frond is needed. A better accuracy for frond 9 is achievable because it is advantageously visible from the top of the canopy as compared with frond 17 , which is located deeper under the canopy.

\section{Acknowledgments}

We would like to thank United Malacca Berhad for the financial support and providing the study area, and Mehrzad Aghajani, Amiratul Diana Amirruddin, and Mohamad Izzudin Anuar for their cooperation in the Ganoderma diagnostic survey and operations in the fields.

\section{Literature Cited}

Abdullah, A. H., Adom, A. H., Shakaff, A. Y., Ahmad, M. N., Saad, M. A., Tan, E. S., Fikri, N. A., Markom, M. A., and Zakaria, A. 2011. Electronic nose system for ganoderma detection. Sens. Lett. 9:353-358.

Alexander, A., Dayou, J., Sipaut, C. S., ChongKhim, P., and LeePing, C. 2014. Some interpretations on FTIR results for the detection of Ganoderma boninense in oil palm tissue. Adv. Environ. Biol. 8:30-32.

Ariffin, D., and Idris, A. S. 1992. The Ganoderma selective medium (GSM). PORIM Information Series, Palm Oil Research Institute Malaysia, Bangi, Malaysia.

Ashourloo, D., Mobasheri, M. R., and Huete, A. 2014. Developing two spectral disease indices for detection of wheat leaf rust (Pucciniatriticina). Remote Sens. 6:4723-4740.

Asrar, G. 1989. Theory and applications of optical remote sensing. John Wiley and Sons. Inc, Toronto, Canada.

Ayala-Silva, T., and Beyl, C. A. 2005. Changes in spectral reflectance of wheat leaves in response to specific macro-nutrient deficiency. Adv. Space Res. 35: 305-317.

Balasundaram, D., Burks, T. F., Bulanon, D. M., Schubert, T., and Lee, W. S. 2009. Spectral reflectance characteristics of citrus canker and other peel conditions of grapefruit. Postharvest Biol. Technol. 51:220-226.

Bauriegel, E., Giebel, A., Geyer, M., Schmidt, U., and Herppich, W. B. 2011. Early detection of Fusarium infection in wheat using hyperspectral imaging. Comput. Electron. Agric. 75:304-312.

Corless, C. E., Guiver, M., Borrow, R., Edwards-Jones, V., Kaczmarski, E. B., and Fox, A. J. 2000. Contamination and sensitivity issues with a real-time universal 16S rRNA PCR. J. Clin. Microbiol. 38:1747-1752.

Darmono, T. W. 2000. Ganoderma in oil palm in Indonesia: current status and prospective use of antibodies for the detection of infection. Pages 249-266 in: Ganoderma Diseases of Perennial Crops. J. Flood, P. D. Bridge, and M. Holderness, eds. CABI Publishing, Wallingford, U.K.

Dayou, J., Alexander, A., Sipaut, C. S., Phin, C. K., and Chin, L. P. 2014. On the possibility of using FTIR for detection of Ganoderma boninense in infected oil palm tree. IJAAEE 1:161-163.

Delalieux, S., Somers, B., Verstraeten, W. W., Van Aardt, J. A. N., Keulemans, W., and Coppin, P. 2009. Hyperspectral indices to diagnose leaf biotic stress of apple plants, considering leaf phenology. Int. J. Remote Sens. 30:1887-1912.

Demetriades-Shah, T. H., Steven, M. D., and Clark, J. A. 1990. High resolution derivative spectra in remote sensing. Remote Sens. Environ. 33:55-64.

Di, W., Cao, F., Zhang, H., Sun, G. M., Feng, L., and He, Y. 2009. Study on disease level classification of rice panicle blast based on visible and near infrared spectroscopy. [In Chinese] Guangpuxue Yu Guangpu Fenxi 29:3295-3299.

Glezakos, T. J., Moschopoulou, G., Tsiligiridis, T. A., Kintzios, S., and Yialouris, C. P. 2010. Plant virus identification based on neural networks with evolutionary preprocessing. Comput. Electron. Agric. 70:263-275.

Govender, M., Dye, P. J., Weiersbye, I. M., Witkowski, E. T. F., and Ahmed, F. 2009. Review of commonly used remote sensing and ground-based technologies to measure plant water stress. Water S.A. 35:741-752.

Grinn-Gofron, A., and Strzelczak, A. 2011. The effects of meteorological factors on the occurrence of Ganoderma sp. spores in the air. Int. J. Biometeorol. 55: $235-241$.

Harini, D. N. D., and Bhaskari, D. L. 2011. Identification of leaf diseases in tomato plant based on wavelets and PCA. Pages 1398-1403 in: World Congress on Information and Communication Technologies.

Hushiarian, R., Yusof, N. A., and Dutse, S. W. 2013. Detection and control of Ganoderma boninense: Strategies and perspectives. SpringerPlus 2:555.

Idris, A. S., Yamaoka, M., Hayakawa, S., Basri, M. W., Noorhisham, I., and Ariffin, D. 2003. PCR technique for detection of Ganoderma. Accessed on January 8, 2016 at http://palmoilis.mpob.gov.my/publications/TOT/tt188.pdf

Karimi, Y., Prasher, S. O., Patel, R. M., and Kim, S. H. 2006. Application of support vector machine technology for weed and nitrogen stress detection in corn. Comput. Electron. Agric. 51:99-109.

Lelong, C. C. D., Roger, J., Brégand, S., Dubertret, F., Lanore, M., Sitorus, N. A., Raharjo, D. A., and Caliman, J. 2010. Evaluation of oil-palm fungal disease infestation with canopy hyperspectral reflectance data. Sensors (Basel) 10:734-747.
Liaghat, S., Ehsani, R., Mansor, S., Shafri, H. Z. M., Meon, S., Sankaran, S., and Azam, S. H. M. N. 2014. Early detection of basal stem rot disease (Ganoderma) in oil palms based on hyperspectral reflectance data using pattern recognition algorithms. Int. J. Remote Sens. 35:3427-3439.

Liu, M., Liu, X., Li, M., Fang, M., and Chi, W. 2010. Neural-network model for estimating leaf chlorophyll concentration in rice under stress from heavy metals using four spectral indices. Biosyst. Eng. 106:223-233.

Liu, Z. Y., Huang, J. F., Shi, J. J., Tao, R. X., Zhou, W., and Zhang, L. L. 2007. Characterizing and estimating rice brown spot disease severity using stepwise regression, principal component regression and partial leastsquare regression. J. Zhejiang University-SCIENCE B. 8:738-744.

Markom, M. A., Md Shakaff, A. Y., Adom, A. H., Ahmad, M. N., Hidayat, W., Abdullah, A. H., and Ahmad Fikri, N. 2009. Intelligent electronic nose system for basal stem rot disease detection. Comput. Electron. Agric. 66: 140-146.

McClelland, J. L. 2015. Explorations in parallel distributed processing: A handbook of models, programs, and exercises, 2nd ed. Stanford University, online. http://www.stanford.edu/group/pdplab/pdphandbook

Moran, M. S., Inoue, Y., and Barnes, E. M. 1997. Opportunities and limitations for image-based remote sensing in precision crop management. Remote Sens. Environ. 61:319-346.

Naher, L., Ho, C.-L., Tan, S. G., Yusuf, U. K., and Abdullah, F. 2011. Cloning of transcripts encoding chitinases from Elaeis guineensis Jacq. and their expression profiles in response to fungal infections. Physiol. Mol. Plant Pathol. 76:96-103.

Naidu, R. A., Perry, E. M., Pierce, F. J., and Mekuria, T. 2009. The potential of spectral reflectance technique for the detection of grapevine leaf rollassociated virus-3 in two red-berried wine grape cultivars. Comput. Electron. Agric. 66:38-45.

Natarajan, S., Bhaskaran, R., and Shanmugam, N. 1986. Preliminary studies to develop techniques for early detection of Thanjavur wilt in coconut. Indian Coconut J. 17:36.

Noh, H., Zhang, Q., Shin, B., Han, S., and Feng, L. 2006. A neural network model of maize crop nitrogen stress assessment for a multi-spectral imaging sensor. Biosyst. Eng. 94:477-485.

Paul, P. A., and Munkvold, G. P. 2005. Regression and artificial neural network modeling for the prediction of gray leaf spot of maize. Phytopathology 95 388-396.

Pourreza, A., Lee, W. S., Ritenour, M. A., and Roberts, P. 2016. Spectra Characteristics of Citrus Black Spot Disease. HortTechnology 26:254-260.

Rees, W. G. 2001. Physical principles of remote sensing, 2nd Ed. Cambridge University Press, Cambridge, U.K.

Rumpf, T., Mahlein, A. K., Steiner, U., Oerke, E. C., Dehne, H. W., and Plümer, L. 2010. Early detection and classification of plant diseases with support vector machines based on hyperspectral reflectance. Comput. Electron. Agric. 74 91-99.

Sanches, I. D. A., Souza Filho, C. R., and Kokaly, R. F. 2014. Spectroscopic remote sensing of plant stress at leaf and canopy levels using the chlorophyl $680 \mathrm{~nm}$ absorption feature with continuum removal. ISPRS 97:111-122.

Shafri, H. Z. M., and Anuar, M. I. 2008. Hyperspectral signal analysis for detecting disease infection in oil palms. Pages 312-316 in Proceedings of International Conference on Computer and Electrical Engineering, Phuket, Thailand. IEEE.

Shafri, H. Z. M., Anuar, M. I., Seman, I. A., and Noor, M. N. 2011. Spectral discrimination of healthy and Ganoderma-infected oil palms from hyperspectral data. Int. J. Remote Sens. 32:7111-7129.

Tawfik, O., Shafri, H. M., and Mohammed, A. A. 2013. Disease detection from field spectrometer data. IIUM Eng. J. 14:133-143.

Thenkabail, P. S., Enclona, E. A., Ashton, M. S., and Van Der Meer, B. 2004 Accuracy assessments of hyperspectral waveband performance for vegetation analysis applications. Remote Sens. Environ. 91:354-376.

Turner, P. D., and Gillbanks, R. 1974. Page 672 in: Oil palm cultivation and management. Incorporated Society of Planters. University Press, Kuala Lumpur, Malaysia.

Wang, X., Zhang, M., Zhu, J., and Geng, S. 2008. Spectral prediction of Phytophthora infestans infection on tomatoes using artificial neural network (ANN). Int. J. Remote Sens. 29:1693-1706.

West, J. S., Bravo, C., Oberit, R., Lemaire, D., Moshou, D., and McCartney, H. A 2003. The potential of optical canopy measurement for targeted control of field crop diseases. Annu. Rev. Phytopathol. 41:593-614.

Yang, Z., Rao, M. N., Elliott, N. C., Kindler, S. D., and Popham, T. W. 2009 Differentiating stress induced by greenbugs and Russian wheat aphids in wheat using remote sensing. Comput. Electron. Agric. 67:64-70.

Zhang, J., Pu, R., Huang, W., Yuan, L., Luo, J., and Wang, J. 2012. Using in-situ hyperspectral data for detecting and discriminating Yellow Rust disease from nutrient stresses. Field Crops Res. 134:165-174.

Zhao, D., Reddy, K. R., Kakani, V. G., and Reddy, V. R. 2005. Nitrogen deficiency effects on plant growth, leaf photosynthesis, and hyperspectral reflectance properties of sorghum. Eur. J. Agron. 22:391-403. 